\title{
Burnout Among Postgraduate Medical Students in Tertiary Hospital
}

\author{
Rampukar Sah \\ Child and Adolescent Psychiatry Department Unit, Kanti Children Hospital, Kathmandu, Nepal
}

Email address:

rampukarsah@yahoo.com

\section{To cite this article:}

Rampukar Sah. Burnout Among Postgraduate Medical Students in Tertiary Hospital. Science Journal of Public Health. Vol. 9, No. 5, 2021, pp. 149-153. doi: 10.11648/j.sjph.20210905.12

Received: June 20, 2021; Accepted: August 6, 2021; Published: September 8, 2021

\begin{abstract}
Medical education is highly stressful, stepping into a new environment, huge course syllabus which has to be mastered in a short period of time besides continuous assessments, examinations and other social and personal issues makes medical student prone to develop negative emotional symptoms. Burnout is a type of psychological stress. Occupational burnout or job burnout is characterized by exhaustion, lack of enthusiasm and motivation, feelings of ineffectiveness, and also may have the dimension of frustration or cynicism, and as a result reduced efficacy within the workplace. To assess the burnout of postgraduate medical students of tertiary level hospital. A cross sectional study was conducted on 198 medical students at Tribhuvan University Teaching Hospital (TUTH) in Kathmandu. Socio- Demographic Performa and Maslach Burnout Inventory were psychometric tools used. Statistical Package for Social Sciences (SPSS), Inc., and Chicago, IL, USA version 21 for windows was used. Among 198 postgraduate medical students, 52\% (N=112) had severe level of burnout present. Burnout was divided into respective sub- scale of personal accomplishment, depersonalization and emotional exhaustion, where $29 \%$ had severe level of depersonalization, $28 \%$ had severe level of emotional exhaustion and $25 \%$ of them had higher level of personal accomplishment. These measures were administered to 198 post graduate medical students (male $=107$, female=91) at Tribhuwan University Teaching hospital. Among the participants, more than half of them had been burnout.
\end{abstract}

Keywords: Burnout, Emotional Exhaustion, Depolarization, Personal Accomplishment, Postgraduate Medical Students

\section{Introduction}

Health professionals have huge responsibility in providing proper health service. However, findings from studies of medical students and young doctors suggest that their own health care is poor [1]; reports show high rates of mental health problems including depression, anxiety [2]; and emotional exhaustion or 'burnout' [3]. This even applies to developing country like Nepal, where there is low availability of medical professionals, for instance 0.17 doctors per $1,000 /$ population and 0.50 nurses per 1,000/population (WHO, 2013).

The term burnout in psychology was coined by Herbert Freuden berger in 1974 [4]. Burnout is a state which is indulge from the psychological pressure which is due to lack of balance between individual's resource and abilities. One can recognize one being burnout through their decreased efficiency, loss of interest in their work, increase frustration and increase irritability. Burnout is result of the high-stress work environment and emotional demands of the job. Maslach and her colleague Michael Leiter, defined the antithesis of burnout as engagement. Engagement is characterized by energy, involvement and efficacy, the opposites of exhaustion, cynicism and inefficacy [5]. Burnout can be explained by the two factors of job demands and job resources, and that exhaustion is correlated to job demands, and that job resources are negatively correlated to disengagement $[6$, $12,13]$. There are six risk factors for burnout: mismatch in workload, mismatch in control, lack of appropriate awards, loss of a sense of positive connection with others in the workplace, perceived lack of fairness, and conflict between values. [5] 


\section{Research Methods}

\subsection{Research Objectives}

To assess the burnout and its type of postgraduate medical students of tertiary level hospital.

\subsection{Research Design}

The study was a descriptive and cross sectional study.

\subsection{Study Site}

The study was conducted at Tribhuwan University Teaching Hospital (TUTH), Maharajgunj, Kathmandu, Nepal. It has total 444 beds, is one of the largest hospital in Nepal, it is one of the part of Maharajgunj Medical campus. It is affiliated to Institute of Medicine, Tribhuwan University.

\subsection{Sampling Method}

The sampling method used in the study was census. A census is the procedure of systematically acquiring and recording information about the members of a given population. It is a regularly occurring and official count of a particular population.

\subsection{Sample Size}

Study population were all the postgraduate medical student at Tribhuvan University Teaching Hospital (TUTH). According to annual report there were 300 students doing their postgraduation, hence all of them were selected for the participation.

Following standardized tools were used:

\subsection{Tools Used}

\subsubsection{Socio- Demographic Performa}

The Performa included name, age, sex, marital status, caste, religion, socio-economic status, residence, type of family, total number of family members, year of residency, use of alcohol and history of substance use. The questions were framed in a manner so as to serve the purpose of the study and to obtain relevant information.

\subsubsection{Maslach Burnout Inventory}

Maslach Burnout Inventory (aMBI) was used. It consists of subscales of emotional exhaustion (EE), depersonalization (DE) and personal accomplishment (PA). Each subscales consists of three questionares. Its reliability on test- retest is 0.82. $[7,8]$

\subsection{Inclusion Criteria}

The inclusion criteria were following:

1) All residents practicing in TUTH hospital, Maharajgunj, Kathmandu, Nepal.

2) Age 25 years to 50 years old.

3) Medical students who give consent to participate in the study.

4) Medical students have worked in the hospital for more than six months.

Exclusion Criteria

The exclusion criteria were following:

1) Residents who are already diagnosed for depression, anxiety or any other form of mental disorders in last six month.

2) MIT students will be excluded.

\subsection{Ethical Considerations}

Ethical clearance was taken from the Institutional Review Board, Institute of Medicine, Tribhuvan University, and Teaching Hospital. Informed and written consent was taken from each participants. Confidentiality was maintained throughout the study. There were no harm done to the participants from the study and no financial burden was done.

\subsection{Procedure}

All the postgraduate medical students of TUTH, meeting inclusion criteria were explained about the purpose of the study. Informed consent was also taken and explained about the confidentiality. All participants who consented to the study filled out the questionnaires descried above.

\subsection{Data Analysis}

Statistical Package for Social Sciences (SPSS), Inc., and Chicago, IL, USA version 21 for windows was used. The results was expressed using mean \pm standard deviation, percentage with 95\% confidence intervals (CI) Values of $\mathrm{p}<0.05$ : significant Chi-square tests were done to find out statistically significant association between independent and dependent variables. Strength of association were further determined by binary logistic correlation.

\section{Results}

Figure 1: Burnout among the Participants.

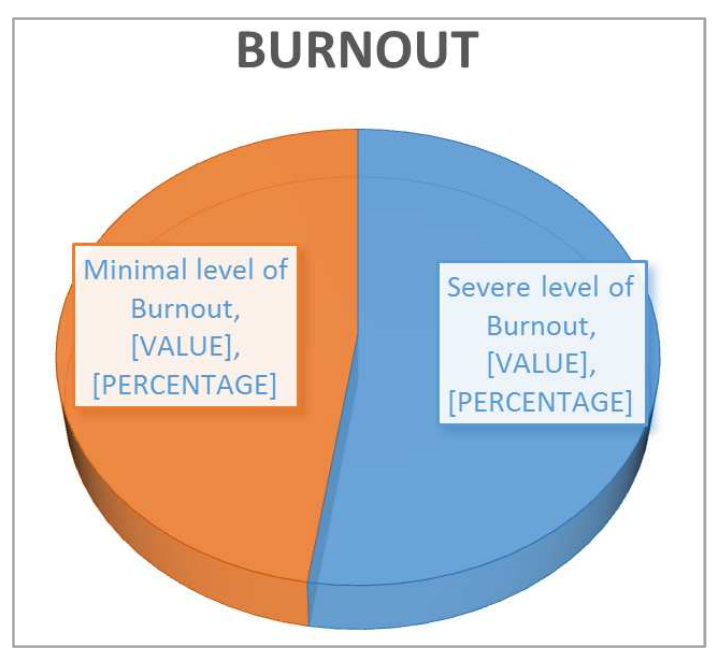

Figure 1. Showed that $52 \%(N=112)$ had severe level of burnout among the participant however $48 \% \%(N=86)$ of them had minimal level of burnout. 
Table 1. Burnout and its Domain's measure.

\begin{tabular}{lllllll}
\hline \multirow{2}{*}{ Domains of Burnout } & \multirow{2}{*}{ Mean Score } & Standard Deviation & \multirow{2}{*}{ Range } & Percentile & \\
\cline { 4 - 7 } & & 3.9 & 18 & 70 & $\mathbf{5 5}^{\text {th }}$ & 78 \\
\hline Personal Accomplishment & 12 & 3.5 & 16 & 62 & 78 & $\mathbf{7 5}^{\text {th }}$ \\
Depersonalization & 4 & 4.6 & 18 & 98 & 58 \\
Emotional Exhaustion & 9 & &
\end{tabular}

The burnout scale consists of three domains which are personal accomplishment, depersonalization and emotional exhaustion. The means score for personal accomplishment was 12 and standard deviation was 3.9, depersonalization mean score was 4 and standard deviation was 3.5 and emotional exhaustion mean score was 9 and standard deviation was 4.6. Among 198 participant 50 participant who had higher personal accomplishment while 58 of them had higher depersonalization and 54 of them had higher emotional exhaustion. Among the participants $25 \%$ of them had higher level of personal accomplishment, 29\% had severe level of depersonalization and $28 \%$ had severe level of emotional exhaustion.

Table 2. Burnout and Socio- Demographic Variables

\begin{tabular}{|c|c|c|c|c|c|c|c|}
\hline \multirow{2}{*}{ Characteristics } & \multirow{2}{*}{ Category } & \multicolumn{6}{|c|}{ Burnout (Mean \pm Standard Deviation) } \\
\hline & & PA & $\mathbf{F}$ & DE & $\mathbf{F}$ & $\mathbf{E E}$ & $\mathbf{F}$ \\
\hline \multirow{3}{*}{ Gender } & Male $(\mathrm{N}=101)$ & $12.7 \pm 4.01$ & \multirow{3}{*}{2.4} & $4.7 \pm 3.9$ & \multirow{3}{*}{$10.1^{*}$} & $10 \pm 4.5$ & \multirow{3}{*}{$10.7 *$} \\
\hline & Female $(\mathrm{N}=97)$ & $11.6 \pm 3.7$ & & $3.1 \pm 2.9$ & & $7.9 \pm 4.6$ & \\
\hline & $20-30(\mathrm{~N}=152)$ & $12.6 \pm 3.4$ & & 4. \pm 3.7 & & $8.9 \pm 4.6$ & \\
\hline \multirow[t]{4}{*}{ Age Group } & $31-40(\mathrm{~N}=44)$ & $10.5 \pm 4.8$ & \multirow[t]{4}{*}{$5.2 *$} & $3.7 \pm 3.3$ & \multirow[t]{4}{*}{0.1} & $9.6 \pm 4.4$ & \multirow[t]{4}{*}{1.5} \\
\hline & $41-50(\mathrm{~N}=2)$ & $10 \pm 2.8$ & & $3.1 \pm 2.1$ & & $4 \pm 2.8$ & \\
\hline & $5000-10000(\mathrm{~N}=15)$ & $13.4 \pm 2.4$ & & $2.7 \pm 2.6$ & & $4.6 \pm 3.6$ & \\
\hline & $11000-15000(\mathrm{~N}=5)$ & $11.6 \pm 2.6$ & & $3.4 \pm 2$ & & $6 \pm 5.4$ & \\
\hline \multirow[t]{3}{*}{ Income } & $16000-20000(\mathrm{~N}=3)$ & $8 \pm 6.9$ & \multirow[t]{3}{*}{1.1} & $2.3 \pm 2$ & \multirow[t]{3}{*}{1.9} & $4.3 \pm 4.9$ & \multirow[t]{3}{*}{$6.2 *$} \\
\hline & $21000-25000(\mathrm{~N}=15)$ & $11.8 \pm 3.5$ & & $6 \pm 3.7$ & & $8 \pm 4.6$ & \\
\hline & $>25000(\mathrm{~N}=160)$ & $12 \pm 4$ & & $3.9 \pm 3.6$ & & $9.7 \pm 4.4$ & \\
\hline \multirow{2}{*}{ Place of Residency } & Rural $(\mathrm{N}=33)$ & $11.7 \pm 4.3$ & \multirow{2}{*}{0.3} & $3.8 \pm 3.5$ & \multirow{2}{*}{0.4} & $8.5 \pm 5$ & \multirow{2}{*}{0.5} \\
\hline & $\operatorname{Urban}(\mathrm{N}=165)$ & $12.3 \pm 3.8$ & & $4 \pm 3.6$ & & $9 \pm 4.6$ & \\
\hline \multirow{2}{*}{ Marital status } & Single $(N=97)$ & $12.6 \pm 3.3$ & \multirow{2}{*}{2.8} & $4.2 \pm 4$ & \multirow{2}{*}{1.1} & $9.2 \pm 4.6$ & \multirow[t]{2}{*}{0.3} \\
\hline & Married $(\mathrm{N}=101)$ & $11.6 \pm 4.3$ & & $3.7 \pm 3.2$ & & $8.8 \pm 4.7$ & \\
\hline & Hindu $(\mathrm{N}=174)$, & $12 \pm 4$ & & $4.1 \pm 3.6$ & & $8.8 \pm 4.7$ & \\
\hline & Buddhist $(\mathrm{N}=13)$ & $11.4 \pm 4.5$ & & $2.9 \pm 2.9$ & & $9.6 \pm 4.3$ & \\
\hline Religion & Islam $(\mathrm{N}=7)$ & $14.4 \pm 2.6$ & 0.7 & $3.7 \pm 4.1$ & 0.6 & $12 \pm 2.3$ & 0.8 \\
\hline & Christian $(\mathrm{N}=1)$ & $14 \pm 0$ & & $0 \pm 0$ & & $12 \pm 0$ & \\
\hline & Others $(\mathrm{N}=3)$ & $13 \pm 2.6$ & & $3.6 \pm 1.5$ & & $9.3 \pm 5.5$ & \\
\hline & Nuclear $(\mathrm{N}=119)$ & $12.5 \pm 3.2$ & & $3.9 \pm 3.3$ & & $9.1 \pm 4.3$ & \\
\hline Type of Family & Joint $(\mathrm{N}=69)$ & $11.5 \pm 4.7$ & 2.7 & $4 \pm 3.9$ & 0.08 & $9 \pm 5.1$ & 0.1 \\
\hline Number of family & $<$ five $(\mathrm{N}=111)$ & $12 \pm 4$ & 005 & $3.9 \pm 3.5$ & 014 & $8.9 \pm 4.4$ & 01 \\
\hline & $>$ five $(\mathrm{N}=87)$ & $12.2 \pm 3.8$ & & $4.1 \pm 3.6$ & & $9.1 \pm 5$ & \\
\hline Use of Substance & Using $(\mathrm{N}=19)$ & $11.4 \pm 4.1$ & 06 & $3.7 \pm 3.5$ & 01 & $8.8 \pm 4.8$ & 005 \\
\hline Use of Substance & Not Using $(\mathrm{N}=179)$ & $12.2 \pm 3.9$ & 0.6 & $4 \pm 3.6$ & 0.1 & $9 \pm 4.6$ & 0.05 \\
\hline & First Year $(\mathrm{N}=101)$ & $12.5 \pm 3$ & & $3.6 \pm 3.1$ & & $8.2 \pm 4.6$ & \\
\hline Residency Year & Second Year $(N=67)$ & $11.7 \pm 4.2$ & 0.7 & $4.7 \pm 4.2$ & 2.5 & $9.7 \pm 4.4$ & 2.1 \\
\hline & Third Year $(\mathrm{N}=44)$ & $11.9 \pm 4.8$ & & $3.4 \pm 3.2$ & & $9.5 \pm 5$ & \\
\hline & No use $(\mathrm{N}=126)$ & $12.1 \pm 3.6$ & & $3.7 \pm 3.4$ & & $8.6 \pm 4.7$ & \\
\hline & Occasional $(\mathrm{N}=19)$ & $12.2 \pm 4.3$ & & $4.7 \pm 3.4$ & & $10 \pm 4$ & \\
\hline Use of Alcohol & $<2$ Year $(\mathrm{N}=10)$ & $12.7 \pm 2.6$ & 0.2 & $4.6 \pm 4$ & 0.5 & $8.6 \pm 5.3$ & 0.7 \\
\hline & 2-5 Year $(\mathrm{N}=10)$ & $11 \pm 5$ & & $4.7 \pm 5$ & & $10.2 \pm 4$ & \\
\hline & $>$ five year $(\mathrm{N}=33)$ & $12 \pm 4.6$ & & $4.1 \pm 3.5$ & & $10 \pm 4$ & \\
\hline & Brahmin $(\mathrm{N}=78)$, & $11.5 \pm 4.4$ & & $4 \pm 3.4$ & & $8 \pm 4.4$ & \\
\hline & Chhetri $(\mathrm{N}=36)$, & $12.2 \pm 3.3$ & & $4.4 \pm 4$ & & $9.5 \pm 4.9$ & \\
\hline & Newar $(\mathrm{N}=43)$, & $12.4 \pm 4$ & & $4 \pm 4$ & & $9.6 \pm 4.6$ & \\
\hline Ethnicity & Tamang $(\mathrm{N}=1)$ & $17 \pm 0$ & 1.1 & $3 \pm 0$ & 0.3 & $13 \pm 0$ & 1.5 \\
\hline & Gurung $(\mathrm{N}=3)$ & $9 \pm 3$ & & $3.6 \pm 3.2$ & & $12 \pm 1.5$ & \\
\hline & $\operatorname{Magar}(\mathrm{N}=2)$ & $11.5 \pm 1$ & & $6 \pm 2.8$ & & $13.5 \pm 5$ & \\
\hline & Others $(\mathrm{N}=35)$ & $13 \pm 3.1$ & & $3.5 \pm 3.1$ & & $9.4 \pm 4.7$ & \\
\hline & Surgical $(\mathrm{N}=43)$ & $13.7 \pm 2.5$ & & $5.1 \pm 4.4$ & & $10.4 \pm 3.8$ & $47 *$ \\
\hline Department & Non-Surgical $(\mathrm{N}=55)$ & $11.6 \pm 4.1$ & $9.6^{*}$ & $3.6 \pm 3.2$ & $6.1^{*}$ & $8.6 \pm 4.8$ & $4.7^{*}$ \\
\hline
\end{tabular}

Note: $*=\mathrm{p}<0.05$.

The study enrolled 198 total participants where majority were males (54\%) than females (46\%). In age group, 
majority (76.8\%) were from 18-30 age group, whereas $22.2 \%$ were from age group of 30-40. Only $1 \%$ were from age group of $40-50$. Majority of them $(83.3 \%)$ were from urban area in comparison to rural area $(16.7 \%) .51 \% \quad(\mathrm{~N}=101)$ of participants were married, whereas $49 \%(\mathrm{~N}=97)$ were single. Among the participants, most of them were from nuclear family $(60.1 \%)$ while $39.1 \%$ were from joint family. Most of the participant were Hindu, which was $87.9 \% \quad(\mathrm{~N}=174)$ followed by Buddhist (6.6\%), Islam (3.5\%) and Christian $(0.5 \%)$. Majority of Participants had monthly income of more than twenty-five thousand were $(80.8 \%)$ and followed by income of 20000-25000 were (7.6\%), 16000-20000 were $(1.5 \%), 11000-15000$ were $(2.5 \%)$ and $5000-10000$ were $(7.6 \%)$. Most the participants were from first year of residency $(43.9 \%)$ while $(33.8 \%)$ were from second year and $(22.2 \%)$ were from third year. Among the participants, most of them had family member less than five $(56.11 \%)$ while $(43.9 \%)$ of them had family member more than five.

Most of them were from Brahmin, 39.4\% $(\mathrm{N}=78)$ followed by Newar $(21.7 \%)$, Chettri $(18.2 \%)$, Gurung $(1.5 \%)$, Tamang $(0.5 \% \%)$ and others were (17.7\%). 63.6\%\% ( $\mathrm{N}=126)$ of participant were not consuming alcohol, however $36.4 \%$ $(\mathrm{N}=62)$ were consuming alcohol. The respondents who were using substance other than alcohol were 9.5\% (N=19) whereas those who did not use were $90.5 \%(\mathrm{~N}=119)$. Most of the participants were from non-surgical department $(78.3 \%)$ while $(21.7 \%)$ were from surgical department.

The above table shows that age group and type of department had significant relation with personal accomplishment, gender (Male $4.7 \pm 3.9$, Female 3.1 \pm 2.9 , P - value 0.04). Type of department (Surgical $5.1 \pm 4.4$, Nonsurgical $3.6 \pm 3.2, \mathrm{P}$ - value 0.03 ) had significant relation with depersonalization. Gender (Male $10.05 \pm 4.5$, Female $7.9 \pm 4.6, \mathrm{P}-$ value 0.02 ), type of department and income (Both P-value 0.006) had significant relation with emotional exhaustion.

\section{Discussion}

Among the postgraduate medical students, 52\% $(\mathrm{N}=112)$ had severe level of burnout present. Burnout was divided into respective sub- scale of personal accomplishment, depersonalization and emotional exhaustion, where $29 \%$ had severe level of depersonalization, $28 \%$ had severe level of emotional exhaustion and $25 \%$ of them had higher level of personal accomplishment. The results showed that personal accomplishment had significant relation with age group and type of department. Depersonalization had significant relation with gender (Male $4.7 \pm 3.9$, Female $3.1 \pm 2.9$ ) and type of department (Surgical $5.1 \pm 4.4$, Non- surgical $3.6 \pm$ 3.2). Emotional exhaustion had significant relation with gender (Male 10.05 \pm 4.5 , Female $7.9 \pm 4.6$ ), type of department and income. Burnout was detected in $14.9 \%$ of the students, and $57.7 \%$ showed a risk of developing the syndrome as reported $[5,9]$. The findings of Tomljenovic et al (2014) contrast with the findings of present study as high levels of emotional exhaustion were $43.6 \%$, depersonalization $33.5 \%$, and lack of personal accomplishment $49.1 \%$ was observed in his study and there was no statistical difference in surgical, nonsurgical which contradict the finding of present study [10]. The result of present study was similar to the study where approximately $20-50 \%$ or more medical students and physicians experience high levels of stress or burnout as reported by A. L, et al (2010). Burnout is prevalent during medical school, with major US multi-institutional studies estimating that at least half of all medical students may be affected by burnout during their medical education. Similarly studies show that variety of personal and professional characteristics correlate well with burnout also support the present findings [11].

The individual's better perception of their professional satisfaction and efficacy leads for higher Personal accomplishment decreases burnout. The subjective sensation of fatigue or stupor related to coping with work leads for emotional exhaustion and it results in low tolerance, a feeling of frustration and irritability and increases burnout. The person's attempt to promote an affective distancing and indifference to work and others through the defensive use of ironic, cold and cynical attitudes leads for depersonalization and increases burnout among the postgraduate medical students.

\section{Conclusion}

Medical education is highly stressful, stepping into a new environment, huge course syllabus which has to be mastered in a short period of time besides continuous assessments, examinations and other social, personal issues makes medical student prone to develop negative emotional symptoms.

These measures were administered to 198 post graduate medical students (male $=107$, female $=91$ ) at Tribhuwan University Teaching hospital. Among the participants, more than half of them had been burnout. The study findings show that the burnout was inversely related to personal accomplishment, positively related to age and more in residents of surgical department than the non-surgical ones. Depersonalization and emotional exhaustion was higher in males than females and those from surgical department. Similarly, emotional exhaustion was higher among those with higher income.

\section{References}

[1] Baldwin P, Dodd M, Wrate RM. Young doctors' health-II. Health and health behaviour. Soc Sci Med. 1997; 45 (1): 41-44.

[2] Kroenke et al. (April, 2007) Anxiety Disorders in Primary Care: Prevalence, Impairment, Comorbidity, and Detection, Annals of Internal Medicine 146 (5): 317-25.

[3] Isaksson K, Gude T, Tyssen R, Aasland EG. Counselling for burnout in Norwegian doctors: one year cohort study. BMJ. 2008; 337: a2004.

[4] Herbert Freuden berger (1974.) Staff Burn-Out JOURNAL OF SOCIAL ISSUES VOLUME 90, NUMBER 1. 
[5] Christina Maslach, Wilmar B. Schaufeli, Michael P. Leiter (2001) Job. Burnout Annual Review of Psychology 52: 1, 397422.

[6] Demerouti. E., Bakker, A. B., Nachreiner, F., \& Schaufeli, W. B. (2001). The jobdemands-resources model of burnout. Journal of Applied Psychology, $86 \quad$ (3), 499. http://dx.doi.org/10.1037/0021-9010.86.3.499

[7] Maslach C, Jackson SE: Maslach Burnout Inventory. 1986, Palo Alto, CA: Consulting Psychologists Press.

[8] McManus IC, Winder BC, Gordon D: The causal links between stress and burnout in a longitudinal study of UK doctors. Lancet. 2002, 359: 2089-2090. 10.1016/S01406736(02)08915-8.

[9] Gilson et al, (2016) Prevalence of burnout syndrome in medical students in brazil Almeida GC et al. / Arch Clin Psychiatry. 2016; 43 (1): 6-10.
[10] Rijeka, et al 2014 Stress, depression and burnout among the hospital physicians in Psychiatria Danubina, 2014; Vol. 26, Suppl. 3, pp 450-458.

[11] F. E, Santos. A. S, Abreu. R. T. A, Enaldo. J. S Melo. V Andrade. M. T Burnout Syndrome and associated factors among medical students: a cross-sectional study Costa. Clinical Psychology Clinics 2012; 67 (6): 573-579.

[12] Zuraida AS and Zainal NZ (2015) Burnout among Malaysian Junior Doctors Using the Abbreviated Maslach Burnout Inventory the Psychological Medicine Research group of University Malaya (PARADIGM), University of Malaya, 50603 Kuala Lumpur, Malaysia.

[13] Zuraida AS and Zainal NZ Exploring (2015) Burnout Among Malaysian Junior Doctors Using the Abbreviated Maslach Burnout Inventory, MJP Online Early. 